\title{
Revision Total Hip Replacement: A Case Report
}

\begin{abstract}
Total hip replacement is a reconstructive procedure that has improved the management of those diseases of the hip joint that have responded poorly to conventional medical therapy. Conventional, primary total hip replacement is a durable operation in the majority of patients. A hip replacement is a mechanical device with parts that are assembled before and during the operation. But the possible complications of total hip arthroplasty, and its clinical performance over time, is a challenging occasion to the surgeons, and such a challenge we faced with our presenting patient. A 68 year old lady with history of cemented bipolar hemiarthroplasty done in a tertiary care hospital, due to fracture neck of the left femur having the history of diabetes, chronic kidney disease, heart disease, anaemia, and mental disorders presented with loosened prosthesis, thinning of medial proximal cortex of the femur which had broken within few months after surgery. She complained of painful walking at left hip joint. There was also evidence of chronic infective and degenerative arthritis of acetabular component of the affected hip joint. Cemented revision total hip replacement surgery was performed with expert multidisciplinary involvement. On 2nd postoperative day the patient was allowed to walk on operated limb with the aid of walker. On 12th postoperative day all the stitches were removed and wound was found healthy.
\end{abstract}

Md. Hafizur Rahman'1, Md. Mohoshin Sarker2, Md. Abdul Matin³

Keywords: Total hip replacement; revision hip replacement; hemiarthroplasty.

Delta Med Col J.Jul 2013;1(2):58-61

1. Professor, Dept. of Orthopedics, Delta Medical College, Dhaka, Bangladesh.

2. Resident Surgeon, Dept. of Orthopedics, Delta Medical College, Dhaka, Bangladesh.

3. Assistant Registrar, Dept. of Orthopedics, Delta Medical College, Dhaka, Bangladesh.

Correspondence: Prof. Dr. Md. Hafizur Rahman. e-mail: mhr@gmail.com

\section{Introduction}

Hip revision surgery, which is also known as revision of total hip arthroplasty - is a procedure in which the surgeon removes a previously implanted artificial hip joint, or prosthesis, and replaces it with a new prosthesis. ${ }^{1}$

Total hip replacement has been one of the most successful operations in orthopedic surgery. By alleviating pain and disability, it has helped patients to return to active life. Several hundreds of thousands hip replacements are conducted every year, worldwide. Hip, the second biggest joint of the human body with its primary role in locomotion, may be exposed to a number of non traumatic and traumatic hazards that may result in the condition known as osteoarthritis.2,3
Regardless of the initial pathology, the end result of this process is nearly always the same, characterized by pain, limitation of movements and impaired locomotor function. A number of surgical methods have been designed and developed for this condition in the past including osteotomies, fusions and resections, but they never provided satisfying results for patients and their doctors. ${ }^{4,5}$ Therefore, the idea of prosthetic replacement of the hip has gradually emerged.

The first attempts to replace the hip joint were made by Dr. Gluck from Berlin (Germany) in 1880. The prosthesis was manufactured from ivory. It was obviously not a success. A second attempt, by French surgeon Jules Pean from Paris in 1890 with the 
prosthesis made from platinum also failed. It was not until 1925 that a subsequent trial took place, this time in the USA by Smith Petersen from Boston. Milestones on this way have been the inventions of a chrome-cobalt alloy characterized by high mechanical and surface resistance, high-density polyethylene and bone cement. Initially, only the femoral head was replaced using cementless. ${ }^{6}$

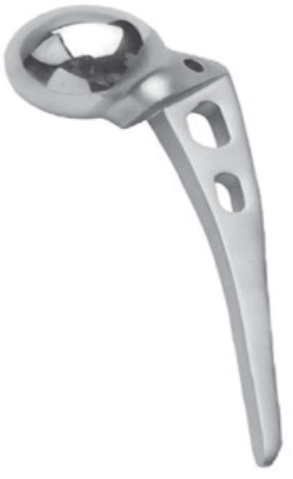

Fig 1: Moore prosthesis

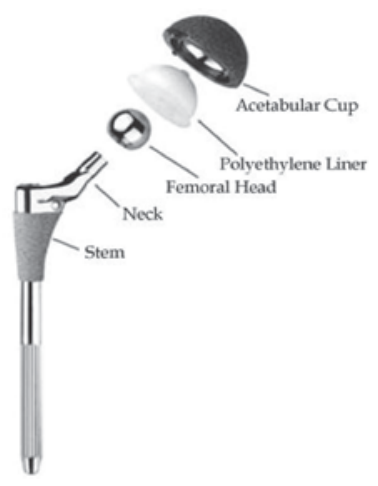

Fig 2: Parts of a total hip prothesis
The first successful series of implantations of the total hip prosthesis (replacing both hip components) with excellent mid term results was reported by Sir John Charnley, a renowned British orthopedic surgeon from Wrightington Orthopedic Center, in the sixties of the last century. The Charnley prosthesis was most successful and long lasting. It became a "gold standard" for hip replacement and is still used in modified versions. ${ }^{6-9}$

The most common condition for which total hip arthroplasty is done is severe osteoarthritis of the hip. ${ }^{10}$ Conditions for which the procedure may be indicated and which predispose to the development of secondary osteoarthritis include developmental dysplasia of the hip, Paget's disease, trauma, and osteonecrosis of the femoral head. Patients with rheumatoid arthritis, other collagen diseases such as systemic lupus erythematosus, and ankylosing spondylitis may benefit as well. The large number of operations performed each year reflects the fact that more than $90 \%$ of appropriately selected patients achieve complete pain relief and notable improvement in function. ${ }^{11}$

Total hip arthroplasty is contraindicated if active infection is present either locally in the pelvic region or elsewhere in the body. ${ }^{12}$ The procedure may be performed through various surgical approaches, and in all techniques, scrupulous precautions are taken to prevent bacterial contamination of the open wound. Prophylactic intravenous antibiotics are used routinely.

Hip revision surgery has three major purposes, like relieving pain in the affected hip, restoring the patient's mobility and removing a loose or damaged prosthesis before irreversible harm is done to the joint. In general, a surgeon will consider revision surgery for pain relief, only when, more conservative measures, such as medication and changes in the patient's lifestyle, have not helped.

Complications which may occur following revision arthroplasty of the hip include anesthesia complications, thrombophlebitis, infection, dislocation, osteoporosis, myositis ossificans, loosening, etc.

\section{Case report}

Although replacement hemiarthoplasty is being practiced randomly for last 12-15 years in Bangladesh, total hip replacement is not so common and is performed in a few selected centres only in last few years. Revision total hip replacement surgery have just started and only few cases are reported.

Our patient was 68 years old female with diabetes, chronic kidney disease, heart disease, anaemia, and mental disorders. About 3 years ago she was admitted at a tertiary care hospital in Dhaka with history of fall followed by fracture neck of the left femur. There she had undergone cemented bipolar hemiarthroplasty operation. Due to post operative infection, the prosthesis was loosen, medial proximal cortex of the femur was thin and broken within few months after surgery. There was also chronic infective and degerative arthritis of acetabular component of left hip joint. She had been suffering from painful walking at left hip joint.

On admission her $\mathrm{Hb} \%$ was $8.7 \mathrm{gm} / \mathrm{dL}$, serum creatinine level was $2.5 \mathrm{mg} / \mathrm{dL}$, random blood glucose was $16.7 \mathrm{mmol} / \mathrm{L}, \mathrm{ECG}$ and Doppler study showed signs of ischemic heart diseases. All those parametrers were well controlled before surgery with contributions of expertise in relavent fields and a revision total hip replacement surgery was performed using cemented prosthesis and metalic acetabular cup through previous 
Moores approch ${ }^{13}$ which was used for hemiarthroplasty also. Previous bi-polar prosthesis was removed cutting the bone cement and all fibrous and scarred tissue. Femoral and acetabular component was prepeared by proper reaming then stem size was determined and fixed with cement maintaining anteversion. Size of acetabular cup was also determined and fixed with cement. Prosthesis was then reduced inserting inner cup. Abductor component of hip joint was preserved by fixation with surgical wire and absorbable suture as well. Under appropiate antibiotic coverage this surgery was performed with epidural anaesthesia which was further continued for two days post operatively for analgesia.

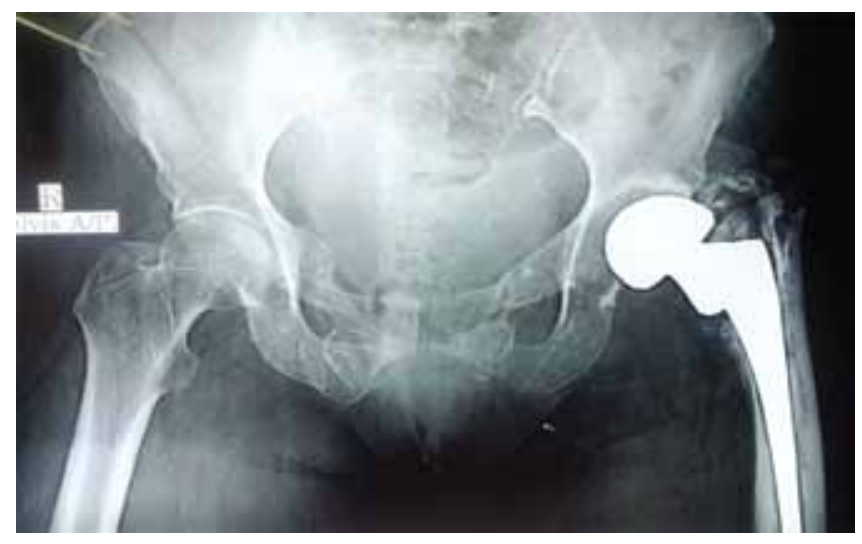

Fig 3: X-ray showing cemented bipolar hemiarthroplasty status with loosen proximal cortex of the femur and degenerative arthritis of acetabular component of left hip joint

On 2nd post operative day all related serological investigations were repeated and corrected accordingly then drain was removed, check dressing was done and patient was allowed to walk on operated limb with the aid of walkar. On 12th post operative day dressings were reopened, wound was found healthy, and then all the stitch were removed.

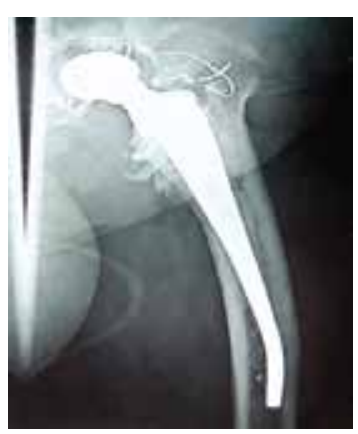

Fig 4: Check X-ray after operation

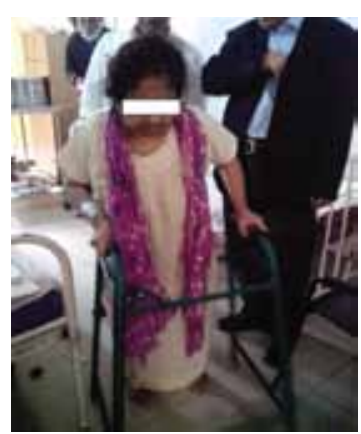

Fig 5: Patient walking on 2nd post operative day
Following operation the patient was able to walk on her operated limb pain free and she could flex the knee and hip joint more than 90 degrees. She could also climb stairs upto 3rd floor. Patient was released with advice to follow instructions of physiotherapist and to maintain some safety measures like using a raised commode seat, bathtub bench, and raised surfaces of couches and chairs at home.

\section{Discussion}

Although the revision hip surgery, is a matter of generations of surgeries, to all countries. In Bangladesh still we are at the stage of beginnings of total replacement of hip surgery, and matter of revision yet a gap of generation. But for the last three decades hemiarthroplasty is going on in Bangladesh, where replacing the head of the femur without cement and sometimes bipolar prosthesis for femoral head is being done, implanted with or without cement. Now, those patients are presenting to us with different types of complications, from loosening due to severe osteoporosis, infections and some times even breakage of the stem of the prosthesis. This patient also was a sufferer of such complications of loosening of the prosthesis due to severe osteoporosis and thinning out of the calcur of the neck of the femur and breakage of the medial cortex of the femur, and thinning out of the floor of the acetabulam, which made her disabled due to instability and severe pain of the hip joint. Besides these orthopedic problems she had several other chronic medical disorders making the management a challenge to the surgeons, and also to the anesthesiologists. With the cooperation of all related concerned, it was possible for us to perform this surgery, post operatively which brought comfort to the patient and made her life easier to manage, brought relief and piece to her family members, and at the same time it is also an inspiration to us, the operating orthopedic team, to perform in future such surgeries in Bangladesh.

\section{References}

1. Cibulka MT, White DM, Woehrle J, Harris-Hayes M, Enseki KR, Fagerson TL, Slover J, Godges JJ. Hip pain and mobility deficits - Hip osteoarthritis. J Orthop Sports Phys Ther. 2009;39(4):A1-A25. 
2. van der Meulen $\mathrm{MCH}$, Allen WA, Giddings VL, Athanasiou KA, Poser RD, Goodman SB, Smith RL, Beaupré GS. Effect of hemiarthroplasty on acetabular cartilage [Internet]. 1996 Project Reports [cited 2013 May 20]. Available from: http:// www.stanford.edu/group/rrd/96reports/96dev5.html.

3. Pearcy MJ. A new generation of artificial hip joints. Eng Med. 1988;17:199-201.

4. Roberts M. Surgeons call for end to metal hip replacements. BBC News Health [Internet]. 2012 March 5 [cited 2013 May 20]. Available from: http://www.bbc.co.uk/news/health-17261234.

5. Geiger M, Ritter MA, Meding JB. Fracture. In: Bono JV, McCarthy JC, Thornhill TS, Bierbaum BE, editors. Revision total hip arthroplasty. New York: Springer; 1998.p.40-42.

6. McKee GK, Watson-Farrar J. Replacement of arthritic hips by the McKee- Farrar prosthesis. J Bone Joint Surg [Br]. 1966;48:245-59.

7. Charnley J. Total hip replacement. JAMA. 1974;230(7):1025-28.
8. Charnley J. Low friction arthroplasty of the hip: Theory and practice. Berlin, Germany: Springer-Verlag; 1979.p.332-45.

9. Morrey BF, Ilstrup DM. Size of the femoral head and acetabular revision in total hip replacement arthroplasty. J Bone Joint Surg [Am]. 1989;71:50-55.

10. Sullivan P, Scott K, Johnston R. Current concepts in hip joint replacement. Iowa Med. 1992; 276:468-69.

11. Rose RM, Nusbaum HJ, Schneider H. On the true wear rate of ultra high molecular weight polyethylene in the total hip prosthesis. J Bone Joint Surg [Am]. 1980;62:537-49.

12. Coté J. Hip replacement is not viewed as high-risk surgery; Death is rare, but underlying medical condition a factor. San Francisco Chronicle [Internet]. 2007 July 22 [cited 2013 May 20]. Available from: http://www.sfgate.com/health/article/Hip-replacementis-not-viewed-as-high-risk-2569128.php.

13. Hemiarthoplasty of the hip - Wheeless' text book of orthopaedics [Internet]. 2013 April 8 [cited 2013 May 20].Available from: http://www.wheelessonline.com /ortho/ hemiarthroplasty_of_the_hip. 